\title{
An evaluation of a stress management intervention for parents of children with Attention-Deficit/Hyperactivity Disorder
}

\author{
Yashica Prithivirajh ${ }^{\prime}$ \\ University of Johannesburg, P.O. Box 291559. Melville, 2109 \\ yashicap@uj.ac.za \\ Steve D. Edwards ${ }^{2}$ \\ Department of Psychology, University of Zululand \\ Sdedward@telkomsa.net
}

\begin{abstract}
The purpose of this study was to evaluate the experiences of parents' participation in a stress management programme for parents with children diagnosed with Attention-Deficit/Hyperactivity Disorder (ADHD). It was expected that the programme would lead to improved parent-child relationships and more positive child behaviour. The qualitative, phenomenological approach included thematic content analysis. The stress management group consisted of 8 parents, 5 mothers and three fathers, who met for 9 consecutive weeks. There were nine sessions focusing on stress, education, resources, problem solving skills, cognitive restructuring, communication skills, self care skills, behaviour management and wrap-up respectively. Process evaluation consisted of a session-by-session description of the programme. Summative evaluation consisted of an appreciative inquiry questionnaire. Additional experiential data was obtained from the ADHD children of participants via an interview with the researcher. The results of the study suggested that the programme was effective. Parents experienced the programme as bringing about empowerment, group cohesion, cognitive restructuring, behaviour modification, growth, development and change. Children viewed their parents as having become more relaxed, approachable, inclusive and loving. An independent psychologist evaluated the programme positively in terms of its quality, effectiveness, flexibility, adaptability and comprehensiveness. While widely acknowledged, the difficulties of parents of children with $A D H D$ are seldom the focus of intervention. The inclusion of a stress management counselling component for parents of ADHD children is recommended as a valuable adjunctive strategy in the overall comprehensive management of $A D H D$.
\end{abstract}

Keywords: Stress management, children with ADHD, Attention Deficit Hyperactivity Disorder, parents - ADHD

\section{Introduction}

Important indirect consequences of children with Attention Deficit Hyperactivity Disorder (ADHD) include effects on parent-child interactions and, more generally, the family environment. The problematic relationship between such children and their parents is best described as a "negative-reactive" response pattern. According to Johnston (1996), this pattern develops when parents of ADHD children react to their child's disruptive behaviours by displaying more commanding behaviour, more disapproval, fewer rewards for compliant behaviour and more overall negative behaviour than parents of normal children. Kazdin and Whitley (2003) also found that the stress of the parent influences parent disciplinary practices which directly promotes and escalates aggressive and oppositional child behaviour; that is, the stress of parents appears to increase parent irritability and attention towards deviant child behaviour. Current research on parenting and ADHD has revealed that ADHD has important consequences to the sufferers, as well as their parents and siblings (Swensen, Birnbaum, Secnik, Marynchenko, Greenberg \& Claxton, 2003). More specifically, there has been a discovery that parents experience greater stress with children with ADHD than other parents with children without ADHD because of the additional parenting challenges they face (Rabiner, 2002). A review of the existing literature on parental stress associated with children diagnosed with ADHD revealed a few quantitatively orientated studies, which were all conducted overseas. Very few published studies focused on parental experiences of parenting a child with ADHD (Anastopoulos, Shelton, DuPaul, \& Guevremont, 1993; Weinberg, 1999; Wells, Epstein, Hinshaw, Conners, Klaric, Abikoff, Abramowitz, Arnold, Elliot, Greenhill, Hechtman, Hoza, Jensen, March, Pelham, Pfiffner, Severe, Swanson, Vitiello, \& Wigal, 2000; Barkley, Guevremont, Anastopoulos, \& Fletcher, 1992; Chronis, Pelham, Roberts, Gamble, Gnagy, \& Burrows-Maclean, 1999; Treacy, Tripp, \& Baird, 2005).

\section{Purpose of the study}

The purpose of the present study was to explore and understand parents' experiences of participating in the Parent Stress Management programme for parents of children with ADHD. If the programme is effective in treating and

I. Yashica Prithivirajh, PhD, is a lecturer in the Department of Education Psychology at the University of Johannesburg, South Africa.

2. Stephen Edwards, PhD, DEd, is an Emeritus Professor and Research Fellow in the Department of Psychology, University of Zululand, South Africa 
managing parenting stress of the participants, then it is hypothesised that parent-child interactions would improve, resulting in more positive child-behaviours. This was investigated via a qualitative evaluation of the programme, using an appreciative inquiry method as well as incorporating aspects of process evaluation. Based upon these informed observations, multidimensional treatment programmes can be recommended for families with children with ADHD.

The critical questions that framed this research were:

- What are the respondent's experiences of the Parent Stress Management Programme for parents with children diagnosed with ADHD?

- What do the respondents appreciate about the Parent Stress Management Programme for parents with children diagnosed with ADHD?

- How can the Parents Stress Management Programme for parents with children diagnosed with ADHD be improved?

\section{Methodology}

A qualitative, phenomenological approach was adopted since the focus of this study was on the experiences of participants in the intervention programme. The study is based in the Umlazi District, Durban Central circuit, in the Ethekwini Region in KwaZulu-Natal. This area is a predominantly Indian suburb with residents falling within average to high socio-economic status. The sample was purposefully selected as the researcher was in private practice at the time of the study. The study was located at the researcher's practice as numerous referrals were made to the researcher via the local schools in that area pertaining to the focus of the study. Pamphlets were distributed to the local neighbourhood, detailing the nature, content and purpose of the study. Consent was also obtained from the participants for their feedback regarding the group to be used for research purposes. Permission to conduct this research was obtained from the researcher's University Ethics Committee.

The sample consisted of 8 participants, 5 mothers and three fathers, all of whom met the following criteria:

I) They had to be parents, either male or female.

2) They had to be parents of a child (6-18 years old) already diagnosed with DSM-IV ADHD.

3) They had to be experiencing difficulty relating to parenting their child/children with ADHD.

The parent stress management group met for 9 consecutive weeks. Each session was approximately two hours in duration. In summary, the programme itself was designed to address the characteristics of the child (ADHD symptoms, associated difficulties), the parent (mood, cognition, parenting efficacy), and the environment (parental relationship, available social support) thought to contribute to elevations in parenting stress. There were nine sessions focusing on stress, education, resources, problem solving skills, cognitive restructuring, communication skills, self care skills, behaviour management and wrap-up respectively. Session content focused on the provision of accurate information to assist parents in developing realistic expectations of their children together with skill training to reduce emotional arousal and to improve communication and problem solving. The group format, in addition to being cost-effective, offered parents the opportunity to discuss their concerns with others facing similar difficulties, potentially increasing their actual and perceived social support.

Process evaluation techniques were utilised in order to evaluate the processes occurring during the course of the programme itself. This was achieved via a session-by-session evaluation of the programme by the researcher. Summative evaluation consisted of an appreciative inquiry questionnaire administered to all participants and an independent psychologist after termination of the programme. The appreciative inquiry questionnaire asked the following three questions: Describe your experiences of the programme. What do you appreciate about the programme? How can this programme be improved?

Data triangulation was carried out by obtaining collateral data from the ADHD children of participants via an interview to concur with what the participants reported. All qualitative data was analysed using thematic content analysis.

\section{Results}

On close examination of the qualitative data, statements with similar, though not identical, meaning were gathered into categories. To enhance interpretation, key phrases were included. The following key themes emerged:

\section{Empowerment}

All participants in this study acknowledged the importance of the education and knowledge component of the programme. They believed it helped them feel "less guilty" for their child's condition because they now know what actually causes ADHD and what does not cause ADHD. This in turn helped them to have more realistic expectations for their children with ADHD. By better understanding their children's behaviour, they changed the way they approached and perceived problem situations. Parents believed that the knowledge and skills which they had acquired through this Inkanyiso, Jnl Hum \& Soc Sci 20I I, 3(I) 
programme, via the content covered in the sessions, made them feel "empowered and confident, not only in themselves, but in all situations, be it in their home, dealing with others, even at work."

"I think it's made me stronger as an advocate and as a parent. I feel more comfortable talking about things that l'm dealing with that might be really upsetting at the time."

"I feel good knowing that I have so much of knowledge on ADHD and the necessary skills to deal with it, such as effective disciplining, dealing with my stress in a better manner, and to be a little more patient when dealing with problems."

Group cohesion

Through this programme, parents gained increased skills, an increased sense of power and a sense of belonging. Participants were able to connect with each other and provided support and skills to deal with the day-to-day issues of raising a child with ADHD. Participants described the group as a place where everything they were experiencing with their child with ADHD was accepted and understood. The group was perceived as being an open place where participants could express their feelings about living with a child who has ADHD and receive support to help them learn to solve any problems that they encountered. Participants' experiences of being a member of this group were viewed as extremely positive.

"I definitely appreciated the group sessions instead of individual sessions because I was able to learn not only from the facilitator, but also from the others in the group and some of the information I received from other group members was very useful."

"By talking with people in similar situations, it fosters a sense of belonging and promotes hope for me."

"Eventually the group felt like members of my family, we share a common bond so when we are together my problems just don't seem so huge anymore."

Role of facilitator

The role and skills of the facilitator are fundamental to the effectiveness of the group (Breakwell, Hammond, Fife-Schaw, 1998).

"The approach of our leader was very important in this parent stress management programme. It was her initiative and assistance that helped get us to where we are now, which is definitely a far better place than where we had been when we started this programme, and for that I thank her."

"Our group facilitator created the perfect environment for our group. She accepted our differences, she never judged us, she placed no pressure on us to speak, she always listened to every one of our stories whether they pertained to the current session or not, she always emphasised the confidentiality issue, and she made us feel comfortable and responsible for the group."

Cognitive restructuring and behaviour modification

The whole focus of this programme was to assist parents to identify maladaptive patterns of thoughts and behaviour and to replace them with more appropriate ones learned from the programme. The key to doing this was for each participant to think about how their thoughts about a situation or event would influence how they felt and behaved.

"The first thing that I changed was thinking of my child as ADHD, he is not ADHD, he has ADHD, it is a condition, it is not him. By doing this I managed to separate the diagnosis from my child, the bad behaviours from him, the rudeness from him, etc. and I began to love him and accept him again and became passionate that together he and I can fight this condition."

"By changing the way I always think about my child as being wrong, the causer of problems and uncontrollable, I changed the way I dealt with problem situations in our home. I started understanding him, listening to what he has 
to say and giving him a fair chance. This changed the way he responded and made the situation easier to resolve. Nowadays, we handle each problem as if it is new and unique, we have no pre-conceived ideas of who did what and who is always wrong, and this has made things so much easier and more peaceful at home."

Change as a parent and as a person

A common theme running through parents' experiences of this parent stress management programme was the idea of change. This reflects the idea that people are constantly changing in response to changing situations.

"The experiences of this programme have helped me become more assertive in my role as a parent and as a person."

"I have learnt to believe in myself and that nobody knows more about my child than I do and this empowers me."

"I was always blamed for our child's condition and felt maybe it really was my fault. Today, I can say that I am not to blame, there is nothing wrong with me. I may not be a perfect parent but who is?"

Responses of psychologist

The psychologist's responses follow:

Effective - "The parent stress management programme appears to prove effective for mothers and fathers of children with ADHD."

Comprehensive - "This programme should be included in the comprehensive management of ADHD. It is easy to understand and user friendly as it involves working directly from the treatment manual."

Adaptability - "Although the group format may not be appropriate for all parents, the sessions can be adapted for use with individuals."

Quality - "It's nice to read a study that is not bogged down with quantitative measuring instruments and stats. I really enjoyed the qualitative aspect of your approach, to me that is where the real quality lies."

Flexibility - "As we discussed, the nice part about this stress management programme is that it is so flexible and comprehensive that it can easily be evaluated either from a qualitative approach (like you have done) or, quantitatively, like the psychologists in New Zealand have done."

Children's responses of observed behaviour changes in parents

The children were asked only one question: "You do know that your mum and dad/mum have been attending a parent programme for several weeks now. Have you noticed any changes in them, or the way they now interact/respond to you? Can you please tell me about them?"

The children that were interviewed commented on the following improvements:

\section{Relaxed}

"I love my mummy the way she is now, she's calmer and more relaxed. Her headaches have stopped and she's not taking any more pills. She used to shout a lot at me and dad but now she's better. I hope she still comes to you."

"I can talk to mummy now without us fighting, she's more understanding and has stopped shouting at me for everything. Did you give her some pills to be calm? Can I have some for later, in case she starts getting cross again, I can give her the pills?"

\section{Approachable}

"Before, when I used to do something wrong, or get into trouble for something I would never tell my mum because she would make it worse. She would shout at me and make me cry, even when it wasn't my fault. Now, she speaks to me nicely and I feel I can tell her stuff." 


\section{Loving}

"I always thought that I was adopted because I was different from my brothers and I knew that my parents didn't love me. These days I think they love me more than the others."

\section{Included}

"Now they care about me, they do stuff with me."

"We now have new rules at home which we all made together, me too, because I am also in this family, dad said that and we must follow the rules."

Participants also believed that the programme could be improved. They made several suggestions. These included separate groups for mothers and fathers, inclusion of a session with the child with ADHD, funding for childcare whilst parents attend the programme, more sessions, and inclusion of the school component in the programme.

\section{Discussion}

The suggestion for administering the programme to separate groups of mothers and fathers, which is based on the experience of a particular couple's discomfort in relation to another couple's family conflict, indicates that continual monitoring of the overall general group atmosphere is needed. While including both spouses in groups enables holistic assessment and intervention for interactions between all parents in relation to their children with ADHD, separate groups may become necessary if individual family conflicts become destructive for the group as a whole. Alternatively separate and/or additional couple counseling may be indicated for any particular couple.

In general, separate gender groups are contraindicated. Traditional family roles, in which mothers do all the nurturing and fathers withdraw into outside work activities, leave mothers overly responsible for the emotional health of all members of the family. Many family researchers recommend sharing the role of nurturing as they have found that traditional roles contribute to dysfunction due to the alienation of the father in the emotional life of the family and the over-functioning of the mother in an impossible attempt to make everyone happy. The advantage of including both spouses in groups encourages the sharing of group and parenting responsibilities in relation to differential parental reactions to stress around parenting of ADHD children.

While the more limited research orientated focus of the present study was on intervention for parental stress rather than behavioural change in children, the suggestion of including the child with ADHD in at least one session seems a valuable one for consideration in future interventions. Most of the research studies to date have focused on the child with ADHD with very few studies also intervening in relation to parental psychological and emotional well being.

Including a school component in the programme would also have addressed parents' concerns regarding their child and interactions with the school personnel. Some parents stated that their child's school is a major source of stress for them. By school personnel understanding ADHD and the impact it has on the child and his or her family, teachers can become more sensitive and empathic in their interactions with these families. Considering that education in South Africa has moved towards mainstream inclusion of learners with special needs, it also seems reasonable to recommend more training on ADHD in teacher training programmes.

One of the possible limitations of this study is that the researcher and the participants shared the same cultural context, therefore the results may not be as applicable to persons from different cultural groups. Little is known about ADHD on the African continent because of lack of resources, problems in access and various other social, economic and political factors. Future research focus on culture and ethnicity are extremely important in the development and management of ADHD, as culture shapes the environment in which behaviour is defined as appropriate or inappropriate (Madu, 2003).

No objective measure of parent functioning was included in this study. Given the significant improvements in parenting style, together with the reported links between parenting stress, parenting practices, and the parent-child relationship, future studies should include objective measures of parent-child interaction quality and parenting style.

Although the parent responses indicate that the programme was successful in achieving its goals, these results are appropriate for a single moment in time, immediately following the completion of the programme. To assess whether significant treatment effects were mainstreamed, six and twelve month follow-up data need to be collected and analysed.

\section{Conclusion}

Despite these limitations, the results of the study suggest that the Parent Stress Management Programme for Parents with ADHD children was effective in bringing about positive changes within parent-child interactions and within the parents 
themselves and also within the children. The negative effects of elevated parenting stress on the parent-child relationship and parenting practices argues for the inclusion of such programmes in the comprehensive management of ADHD. Treatment for ADHD should focus on enhancing parents' coping resources as well as directly targeting the child's symptoms and associated difficulties. Reducing parent distress may also help increase the effectiveness of other treatment components, including parent management training.

The current study appears to be the first to target the parenting stress of parents of children with ADHD in South Africa. In doing so it makes two important contributions to the field. First, it draws attention to the needs of parents of children with ADHD. While widely acknowledged, the difficulties of parents of children with ADHD are seldom the focus of intervention. Secondly, the programme components together offer an innovative and promising addition towards the comprehensive management of ADHD.

\section{References}

American Psychiatric Association. (2000). Diagnostic and Statistical Manual of Mental Disorders. (4 ${ }^{\text {th }}$ ed. Text Revision). Washington DC: APA.

Anastopoulos, A.D., Guevremont, D.C., Shelton, T.L., \& DuPaul, G.J. (I992). Parenting stress among families with attention deficit hyperactivity disorder. Journal of Abnormal Child Psychology, 20, 503-520.

Anastopoulos, A.D., Shelton, T.L., DuPaul, G.J., \& Guevremont, D.C. (1993). Parent training for attention deficit hyperactivity disorder: Its impact on parent functioning. Journal of Abnormal Child Psychology, 2I, 58I-596.

Barkley, R.A. (1998). Attention-deficit hyperactivity disorder: A handbook for diagnosis and treatment (2 ${ }^{\text {nd }}$ ed.). New York: The Guilford Press.

Barkley, R.A., Karlsson, J., \& Pollard, S. (1985). Effects of age on the mother-child interactions of hyperactive children. Journal of Abnormal Child Psychology, 13: 631-638.

Barkley, R.A., Guevremont, D.C., Anastopoulos, A.D., \& Fletcher, K.E. (I 992). A comparison of three family therapy programs for treating family conflicts in adolescents with attention deficit hyperactivity disorder. Journal of Consulting and Clinical Psychology, 60, 450-462.

Becvar, D.S. \& Becvar, R.J. (1996). Family Therapy: A Systemic Integration. Boston: Allyn and Bacon.

Befera, M. \& Barkley, R.A. ( 1984). Hyperactive and normal girls and boys: mother-child interactions, parent psychiatric status, and child psychopathology. Journal of Child Psychology and Psychiatry, 26: 439-452.

Breakwell, G.M., Hammond, S., \& Fife-Schaw, C. (1998). Research Methods in Psychology. London: SAGE Publications Ltd.

Chronis, A.M., Pelham, W.E., Roberts J.E., Gamble, S.A., Gnagy, E., \& Burrows-Maclean, L. (I999, November). Two approaches to managing stress in parents of children with ADHD. Poster session presented at the annual meeting of the Association for Advancement of Behavior Therapy, Toronto.

Cunningham, C.E., \& Barkley, R.A. (1979). The interactions of normal and hyperactive children with their mothers in free play and structured tasks. Child Development, 50: 217-224.

Henker, B. \& Whalen, C.K. (1989). Hyperactivity and attention deficits. American Psychologist, 44: 21 6-223.

Johnston, C. (1996). Parent characteristics and parent-child interactions in families of non problem children and ADHD children with higher and lower levels of oppositional-defiant disorder. Journal of Abnormal Child Psychology, 24: 85- 104.

Kazdin, A.E. \& Whitley, M.K. (2003). Treatment of parental stress to enhance therapeutic change among children referred for aggressive and antisocial behaviour. Journal of Consulting and Clinical Psychology. 7 I (3): 504-5 I 5.

Madu, N.S. (2003). Contributions to Psychotherapy in Africa. Polokwane (Pietersburg): UNIN Press.

Mash, E.J. \& Johnston, C. (1982). A comparison of motherhood interactions of younger and older hyperactive and normal children. Child Development, 53: I37I-I38I.

Patton, M.Q. (1987). Qualitative research and evaluation methods ( $3^{\text {rd }}$ ed.). Newbury Park, CA: Sage Publications, Inc.

Rabiner, D. (2002). Stress and coping in parents of children with ADHD. Attention Research Update. Available online at: http:// www.helpforadd.com (Retrieved January 2007).

Swensen, A.R., Birnbaum, H.G., Secnik, K., Marynchenko, M., Greenberg, P., \& Claxton, A. (2003). ADHD: Increased costs for parents and their families. American Academy of Child and Adolescent Psychiatry. 42 (I 2): I 4 I 5-I 423.

Tallmadge, J. \& Barkley, R.A. (1983). The interaction of hyperactive and normal boys with their mothers and fathers. Journal of Abnormal Child Psychology, II: 565-579.

Treacy, L., Tripp, G., \& Baird, A. (2005). Parent Stress Management Training for Attention-Deficit/Hyperactivity Disorder. Behaviour Therapy, 36: 223-233.

Webster-Stratton, C. (1990). Stress: A potential disrupter of parent perceptions and family interactions. Journal of Clinical Child Psychology, 19: 302-312.

Weinberg, H.A. (1999). Parent training for attention deficit hyperactivity disorder: Parental and child outcome. Journal of Clinical Psychology, 55, 907-913.

Wells, K.C., Epstein, J.N., Hinshaw, S.P., Conners, C.K., Klaric, J., Abikoff, H.B., Abramowitz, A., Arnold, L.E., Elliott, G., Greenhill, L.L., Hechtman, L., Hoza, B., Jensen, P.S., March, J., Pelham Jr., W., Pfiffner, Severe, J., Swanson, J., Vitiello, B., \& Wigal, T. (2000). Parenting and family stress treatment outcomes in attention deficit hyperactivity disorder (ADHD): An empirical analysis of the MTA study. Journal of Abnormal Child Psychology, 28, 543-553.

Inkanyiso, Jnl Hum \& Soc Sci 20I I, 3(I) 